\title{
Aurora Bertrana. Dues novel-les sobre el món dels infants: Camins de somni i La nimfa d'argila
}

\author{
Catalina Bonnín Socias
}

\section{LA IDEALITZACIÓ DE LA SEVA PRÒPIA INFÀNCIA}

A la tomada de l'exili l'any 1949 Aurora Bertrana deixà de banda el món de l'exòtic (encara que no totalment) i seguí un canvi d'interessos temàtics: dues obres sobre la infancia i dues sobre la Segona Guerra Mundial. Camins de somni i La nimfa d' argila representen una idealització de la seva pròpia infància, encara que el protagonista d'ambdues sigui masculí. Hi reviu el paisatge de la infantesa, una dida o mainadera (Carolina o Teresa), rondallaire i supersticiosa, que convida al somni i a la fabulació. La passió per la mar. Alhora, el camí difícil cap a la vida adulta. La diferència és que Miquel, de Camins de somni, mai no serà capaç d'accedir-hi, ja que viu en un somni continu. El protagonista de La nimfa d'argila, Jaume, supera la prova i s'encamina cap a la vida adulta mentre va abandonant la poesia pel camí. El pare de Miquel sembla ben bé Prudenci Bertrana, company de llargues passejades amb el fill/a. L'americano convida Miquel a passar alguns dies a Blanes amb ell i la seva família. Jaume rep la revelació brutal del sexe a la platja i s'està tot l'estiu tocant el piano i negant-se a sortir. Tot de detalls autobiogràfics apareixen a les dues novel-les, escrites amb una gran sensibilitat $i$ des del punt de vista dels infants. La segona també presenta una oposició entre burgès i artista que igualment entra en el seu panorama biogràfic. No cal més que recórrer a la primera part de les seves memòries ${ }^{1}$.

1 Bertrana, Aurora. Memòries fins al 1935: Barcelona: Pòrtic, 1973. 


\section{CAMINS DE SOMNI}

L'enfant et la mer, primera versió d'aquesta novel-la en francès, va ser començada a l'Haute Saöne l'any 1946 i acabada l'any següent als Pirineus Orientals, segurament a Prada ${ }^{2}$. Va ser publicada amb el títol Vértigo de horizontes en castellà per l'editorial Torrell de Reus l'any $1952 \mathrm{i}$, finalment, la versió que comentam fou publicada per Albertí a la «Nova Col-lecció Lletres», núm. 13, l'any 1955. L'edició castellana i la catalana presenten molt poques diferències, encara que n'hi ha una d'important. La persona verbal de la novel.la en castellà és la primera: Miquel ens conta ell mateix la història. En canvi, Camins de somni és relatada per un narrador omniscient; per tant utilitza la tercera persona verbal.

La versió en castellà és dedicada a la memòria del pare de l'autora i conté una introducció. Aquesta introducció és per alertar els lectors habituals que aquesta novel-la és molt diferent dels seus altres llibres de viatges. Si bé el protagonista víatja per tot el món, els paisatges són deformats per la idiosincràsia d'un visionari. El drama del personatge radica en la seva impossibilitat absoluta de fer front a la realitat. En definitiva, és una ànima a través dels seus somnis. A part d'aquestes idees essencials que informen el lector, aquesta introducció ofereix gairebé un resum de la novel.la.

Com ja s'ha comentat, és un narrador omniscient qui ens conta la història, sempre des del punt de vista de Miquel, tant quan és un infant molt petit com quan és un adult transformador de la realitat. En aquest sentit, la versió catalana i la castellana varien des del punt de vista formal, però no es diferencien gaire en el contingut ni els efectes, ja que el punt de vista és sempre del protagonista.

Camins de somni té una estructura totalment lineal, de novel-la-riu, que ressegueix tota la vida del protagonista. El text és conformat per tres grans capítols, cada un dels quals correspon a una de les etapes de la vida: infancia i adolescència, maduresa i vellesa. Dins aquests, algunes seqüències són separades per un signe convencional. El primer capítol és més llarg i més complet que els altres dos, els quals deixen grans lapses de temps buits $i$ expliquen alguns detalls succintament mitjançant anacronies.

L'argument és ben simple: Miquel, educat per un pare afectuós i una dida fabuladora, viu una infância de somnis fins que, a l'adolescència, rep la decepció de l'amor, emmalalteix i es fa mariner com a única solució. A la mar viurà un somni etern del qual no tomarà mai, encara que a la vellesa és conscient de l'abandó de què ha fet objecte el seu pare i la dida.

2 Es troba al Fons Bertrana, de la Biblioteca Barri Vell de Girona. 


\section{L'ESTIL I EL LLENGUATGE}

En aquesta història estibada de somnis i d'il-lusions, la part descriptiva hi té una gran importància: la natura, el jardí $i$, sobretot, la mar. La mar és descrita en totes les seves variants, calmada i tempestuosa. Sempre present dins la vida del protagonista, la mar pren categoria de personatge per si mateixa en una descripció excel-lent del Santo Domingo (el vaixell on navega Miquel) que podem llegir a les pàgines 84 i 85 . Primer la mar encalmada, després la mar enfurida per mor dels vents alisis... La mar que bressola el vaixell és totalment captivadora. No debades és l'enamorada de Miquel.

És una novel-la amb pocs diàlegs. Miquel gairebé no parla i, quan vol ferho, no li surten les paraules. Carolina té una gràcia de parlar popular:

- Oidà-seguia Carolina irònicament implacable-, jo en conec un. que es passeja de cap a cap del dia userdars i blatdemorars enlla. Coneix els conreus per terrós, herba per herba. Oh, no pas que els treballi, això ho deixa per als altres, $s$ 'hi xala mirant-los, veus ací (pàgs. 39-40).

Però de la seva boca de vegades no surten retrets, sinó llegendes i mites, i aleshores el seu llenguatge és hiperbòlic i engrescador. Va ser ella qui va imbuir a en Miquel el deliri de la mar.

El pare és més sec, més de la terra, també més realista. El seu parlar és concret i popular, amb mots expressius i frases fetes, com galifardeu, bordegàs, estàs carregat de romanços... Quan es presenta l'americano s'esdevé una barreja de català $i$ castellà d'Amèrica, amb una entonació especial i arrossegant, que Miquel tot d'una percep.

Durant l'acció a Catalunya hi ha gran quantitat de topònims: La Rodona, la Mare de Déu dels Ângels, la Font del Rei, la Font Picant, la Font Pudenta, Blanes, Sant Pol de Mar,... A partir del començ de l'aventura els topònims deixen de tenir sentit.

\section{EL TEMPS I L'ESPAI}

La història se situa més o menys a tombant del segle XIX. És l'època de les emigracions a les Ameriques, de les quals hom tornava amb fortuna o no tomava. La durada de la història és tota una vida. La datació és ben concreta als primers anys de la vida del protagonista: a un o dos anys, als quatre anys, als dotze, i d'aquí a l'adolescència. A l'època de la maduresa se'ns informa que es 
va fer mariner als tretze. A partir d'aquesst moment hi ha un lapse de temps molt gran, buit de contingut però no de significat. El protagonista, enamorat de la mar $\mathrm{i}$ decebut de l'amor humà, es dedica intensament a la vida de mariner: aprendre de menar un vaixell, encantar-se per la bellesa de les aigües i del cel, dels contrallums del sol i dels estels, i també barallar-s'hi quan la mar s'encabrita. De tant en tant, un port on esplaiar-se, engatar-se, conèixer dones $i$ altres cultures. Miquel pren consciència que s'ha oblidat de la seva família i decideix tornar al seu país. Però tanmateix Miquel no té arrels, al contrari del seu pare, que viu ben aferrat a la terra. Un altre lapse de temps buit indica que Miquel ha oblidat la promesa que s'havia fet a si mateix: tornar a Catalunya. Distret de tot per culpa de la mar han continuat passant els anys i ell no se $n$ 'adona fins que un dia el mirall li torna la imatge d'un home vell. Ha de menar el timó i és aquest que li ha de donar suport perquè, en recordar tota la seva vida, ha perdut el món de vista.

Poc després, Miquel ja no fa de mariner. Una anacronia ens informa que el capità li va dir que era massa gran per ser-ne. Per això es comprà una cabana de bambú $\mathrm{i}$ un tros de terra generosa en fruits amb els pocs estalvis que tenia. Ara cada dia va a vorera de mar, escolta les onades, i aquestes acaben per comunicar-li el perdó del seu pare.

Pel que hem explicat fins ara es desprèn que hi ha dos espais ben diferents: un delimitat, que es Catalunya, concretament La Rodona de Girona, on viu Miquel en companyia del seu pare, de la seva mare (molt poc temps) i de la seva dida. El jardí, la terra que els envolta, són descrits amb molta cura i abundància de topònims. Té gran importància l'ermita de la Mare de Déu dels Àngels, el lloc des d'on Miquel va albirar la mar per primer cop a la seva vida. Igualment a Catalunya, un altre espai important $i$ limitat és la casa de Francesc a Blanes, on Miquel resta fascinat per Leonor, on emmalalteix i també on aconsegueix el permís per abandonar els estudis, la terra ferma i per partir cap a la mar.

L'altre espai és il-limitat: la mar immensa, els ports, les gents diverses. Però sobretot la mar i el vaixell, sempre l'un amb l'altre com dos enamorats. La situació concreta ja no té importància:

El fet s'esdevingué a Port-de-France o a La-Pointe-à-Pitre. Potser a Balboa o a Colom... tant se val, en una d'aquestes maleïdes rades abandonades de tots els vents... (pàg.76).

Aquest espai incommensurable i enlluemador, de fet, ha estat sempre dins Ia imaginació de Miquel $i$ ha condicionat tota la seva vida. I quan deixa la mar és perquè ja és vell i no li és permès navegar; viu a terra ferma, però continua amb la seva obsessió de mariner i es passa tot el dia devora la mar conversant amb les ones. 


\section{ELS PERSONATGES}

Miquel, el protagonista, és un infant somniador i sensible. La mort de la seva mare, la nina de cera, és tot un misteri, però en realitat no l'enyora gaire, perquè la dida, Carolina, la supleix perfectament. La dida, a part d'oferir-li l'aliment del seu cos, sap contar històries: històries meravelloses o escarrufadores; històries sobre la mar i els mariners. Degut a les històries de la dida, a Miquel, l'atrau la mar sense conèixer-la.

Així com va creixent, Miquel és un infant solitari. Es passa hores $\mathrm{i}$ hores al jardi observant les coses i els éssers que s'hi troben, flors, insectes. Ensuma els olors penetrants de les flors i de la frujta madura. Amb el temps, l'olor del cascall es convertirà en l'olor de la seva infância. El seu afecte pels animalons fa que consideri la pesca com un assassinat, encara que per molt que s'ho proposi no és capaç de negar-se a menjar el peix cuinat que ha pescat el seu pare durant la diada d'excursió conjunta. Tampoc no pot suportar la presència del carnisser, ni tan sols al ball, perquè encara sent aquella olor de sang a les mans ensagnades del dia de matances.

Miquel té una gran imaginació. Els sifons, per exemple, el distragueren una temporada del seu delit per la mar, i era tota una aventura anar a comprarne i triar el color que tingués els reflexos més espectaculars a contrallum. Quan feia vent, es mirava entre fascinat $i$ esporuguit les peces de roba esteses que adquirien vida de sobte: homes sense cap ni mans amb el ventre inflat, cames sense tors ni peus ballant danses grotesques... El ferrocarril li havia semblat un rèptil corrent com un esperitat. Carolina li donava les explicacions adequades a cada cas i el calmava, però li continuava parlant de la mar de manera fascinant.

Miquel era un infant intel-ligent. Percebia perfectament les reaccions dels adults, moltes vegades contradictòries. Però era un mal estudiant. Només li agradava la geografia $\mathrm{i}$ tothora contemplava els mapes que penjaven de la paret: taques grogues i roses envoltades d'immensos espais blaus.

Quan arriba Francesc, el germà de llet del pare, Miquel comprèn que els dos germans són completament diferents, però la possibilitat d'estar unes setmanes a la mar l'engresca. I s'esdevé una cosa amb la qual Miquel no comptava: l'amor. Decebut de les dones que assistien als balls de la Rodona, Leonor li sembla un ésser extraordinari. Tothom gira entorn d'ella. Obsedit per Leonor i la seva indiferència Miquel emmalalteix. I ja ningú no podrà apartar-lo de la mar, que és la seva obsessió.

Encara que Miquel sabia qui era la seva mare, sempre asseguda a una butaca, malalta, sense forces ni per sostenir el seu fill, era Carolina qui li donava o li negava el pit, qui en tenia cura i qui l'enamorava amb les seves històries, de les quals el pare de vegades es burlava. Era una dona simple i supersticiosa, de família marinera. Li recava ser una dona, ja que, d'haver estat un home, també 
hauria fet de mariner. Carolina tenia al capçal del llit una litografia amb un veler navegant enmig d'una tempesta devora la Mare de Déu del Carme. Esguardava una i altra imatge amb la mateixa devoció, però Miquel pensava que la dida pregava més sovint al vaixell que no a la verge. El pare de Miquel opinava que era l'honradesa en persona i una dona de sa casa com no n'hi ha, encara que de vegades l'acusàs de gandul, gastant un excés de confiança. A Miquel li agradava perquè era de natural alegre i per la seva fecunda imaginació $i$ el seu poder de transformar les coses. Carolina era molt estimada en aquella casa i Miquel se'n sentia orgullós. Amb els anys, la dida anà perdent aquell èmfasi en les histories $i$, a les acaballes de la seva vida, tomà una persona irascible i cridaire.

Marcel-lí Siquiés és el pare de Miquel. És alt, té una barba negra, uns ulls castanys $i$ afectuosos $i$ unes dents blanques $i$ ben posades. Quan es passeja per les vores del Güell amb el fill a la mà les dones el miren amb somriures d'admiració. És un amant de la natura: vagareja pels camps i per les platges del Ter amb una curiositat $i$ un plaer inesgotables. Però mai no ha somniat d'anar a la mar. Miquel sabia que el pare estava enamorat de la terra i tenia por que mai no comprengués el seu entusiasme per la mar. Però ell era un bon pare, comprensiu i tolerant. Quan Miquel era petit, per dormir-lo, li cantava lieders de Schuman i Schubert, fragments de Beeethoven i òperes de Wagner. Volia que el seu fill tingués estudis, però quan Miquel suspenja era incapaç d'enfadar-se. Miquel perdia la gana, la son, empal-lidia i es desencaixava. Aleshores el pare en lloc de renyar-lo li dedicava paraules de consol i precs d'esmena, amb la qual cosa augmentava la pena del seu fill.

El seu fons humà i ètic era millor que el de Francesc, el germà de llet, el qual havia fet fortuna fent treballar esclaus i comprant funcionaris. Eren radicalment diferents:

Francesc estava qui-sap-lo orgullós d'haver-se enriquit, el pare ho estava encara més d' haver romàs pobre. S'esguardaven l'un a l'altre amb una vaga compassió com si en llur intern cadascú donés gràcies a déu d'haver-li conservat l'enteniment mentre el negava al seu germà (pàg. 48).

Miquel era ben conscient d'aquestes diferències:

Miquel pegà llambregada al pare. Pobre home! Semblava que les lloances a paisos exòtics l' ofenguessin personalment. Per ell no hi havia res més formós que la plana gironina, terra de lentes primaveres, $d$ 'horitzons limitats, terra de blat, d' userda, d'ordi i de moresc de flors silvestres de noms senzills: margaridetes, roselles, blauets, gencianes... Terra on tot ếs aspre i reduit, intim i equilibrat, on mai hom no diu adjectius tals com "vastíssim», «embriagador», "misteriós»... (pàg. 49). 
Els dos germans de llet només coincidien en una cosa: havien perdut la dona de molt joves.

Marcel-lî estima el seu fill, per això consent que dugui a terme la seva passió. Per això mateix, també, passa el final de la seva vida a la vora de la mar esperant algun vaixell que li porti el seu fill. Aquesta actitud fa que la gent el prengui per boig.

Francesc i Leonor tenen poc relleu com a personatges, però són importants com a suports de l'acció. Francesc, com ja hem vist, és el germà de llet de Marcel-lí, que s'ha enriquit a Amèrica. Ha visitat el germà després de vint anys perquè ha vingut a Blanes a passar l'estiu amb els fills i la seva institutriu. Els trets que més destaquen són la seva manera de parlar i la seva teoria comercial basada en la corrupció. És l'antítesi del seu germà. Convida Miquel a passar l'estiu amb ells i aquest accepta perquè mai no ha vist la mar de prop.

Leonor, descrita com una nina bella i aviciada, malaltissa, fascina Miquel, decebut de les dones que veia als balls de la Rodona. Però la seva inseguretat $i$ la manca de decisió per atrevir-se a parlar-li el fan emmalaltir. Aquesta frustració amorosa l'empeny a la mar i la malaltia li procura el permís patern.

\section{VISIÓ DE CONJUNT}

Aquesta és una novel-la d'aventures atípica, perquè els camins recorreguts, tal com ens indica el títol, gairebé no pertanyen a la realitat. Decebut de la vida del terròs, prosaica $\mathrm{i}$ grollera. Miquel aixeca les ales cap als somnis de la seva infancia. Viu la realitat i les il-lusions que de nin exercia en el seu jardí, tot capbussant-se en una bassa pudenta.

En realitat, poca cosa se'ns transmet de la seva vida adulta. Tan sols que el contacte intens $i$ absorbent amb la mar han fet de Miquel un home incapaç de percebre el pas del temps. I, a partir de la informació d'un passatger, també un home que té remordiments i que ha madurat un xic: el pare jove i trescaire, la dida xerraire i contenta, el jardí de la Rodona, ja no existeixen. S'han profanat els seus records d'infant.

Però la personalitat de Miquel no ha canviat: se sotmet a la seva passió per la mar i la navegació i continua passant el temps fins que ja és un vell. El pare, mort segurament, Ji envia laments i retrets mitjançant la mar remorosa fins que s'esdevé el miracle: el pare torna jove una altra vegada, somriu, l'ha perdonat. L'home somniador ha tornat a transformar la realitat. Era el que li mancava per reconciliar-se amb la mort.

A part d'algunes descripcions de la mar molt ben assolides, i també de la terra gironina, la vàlua d'aquesta novel-la rau en la primera part, quan 
Miquel és un infant. No és estrany que Miquel es meravelli per les històries de Carolina:

Dins l'aigua, profundament blava, tan quieta $i$ transparent com una capça [sic] de cristall, viuen les sirenes vestides d'escata de peix amb cabellera d'algues. S'alimenten de cargolins i de flors de corall. Sols es mostren en la nit, quan el cel es marceix i ja no escapa gota de llum, quan les ones s'encalmen $i$ el mar es tenyeix de morat i de gris. Si hom si atansa llavors pot oir llurs veus enciseres (pàgs. 10-11).

La penetració psicològica de l'autora per comprendre i interpretar el món dels infants és considerable. La imaginació, les il-lusions, les manies per certs objectes: el poder transformador de la llum a través dels sifons, el tic-tac del rellotge que Miquel no podia suportar quan estava malalt i que en estar sa retornava el record de la malaltia, són dèries que els adults no poden comprendre $\mathrm{i}$ que per als infants poden suposar vertaderes meravelles o vertaders turments.

Entremig dels adults, de vegades els infants se senten sols i desconcertats:

... misteris que Miquel no cercava pas de comprendre. El prec de Carolina, semblava oposar-se a l'afirmació del pare. Miquel, però, havia observat que les persones grans estan sovint en contradicció amb elles mateixes, quan hom els demana aclariments s'enutgen i us envien al diastre (pàg. 15).

\section{LA NIMFA D'ARGILA}

Aquesta novel.la es va publicar el febrer de 1959 a la «Nova Col-lecció Lletres» d'Alhertí. Va rebre el premi Ramon Llull dels Jocs Florals de la Llengua Catalana a l' exili el 14 de juny del mateix any3. L'any 1964 se'n va publicar una traducció al francès que du per títol Matinales, feta per l'amiga Toinet de Montmollin a Ginebra 4 .

Es tracta d'un relat en primera persona verbal, és a dir, és el mateix protagonista el qui ens conta la història a partir del record de fa cinquanta anys. Tanmateix, encara que és un home de gairebé seixanta anys el qui ens conta la seva infancia, la percepció que rebem dels fets és la d'un infant, no han passat pel sedàs de la interpretació de la maduresa. Només a la darrera pàgina el protagonista fa una mena de sentència des de les envistes de la vellesa, la qual sembla pertànyer més a l'autor que no al narrador.

3 Cap d'Any, Raixa, 1960. «Notícies de fora de les lletres catalanes», pàg. 86.

4 Bertrana, Aurora. Matinales. Trad. D'Antoinette de Montmollin. Sant-Aubin (Suïsse): À Ja Baconnière, 1964. 
Tractant-se d'una autobiografia infantil, l'estructura és molt lineal. Encara que no se'ns informa de l'edat del protagonista, deduïm que comença als 4-5 anys i acaba quan aprova l'ingrés al batxillerat, és a dir, als deu anys.

La novel.la s'estructura en nou capítols, sis dels quals porten un nom de pila, referent força important per al protagonista en el moment que s'explica (Teresa, Marià, Salvador, Hilari, Elvireta...); els altres tres són encapçalats per una frase molt significativa del contingut (Cortesia a la mort, Adéu siau, amor...).

De bon principi Jaume ens presenta la seva mainadera i els passeigs que fa amb ella. És una dona jove que té poders extrasensorials. Apareixen anècdotes entorn d'aquesta capacitat, que impressionen Jaume $i$ xoquen amb la mentalitat realista dels seus pares. Quan l'acomiaden, Jaume emmalalteix de tristesa. Però l'oncle Salvador, pintor bohemi malconsiderat per la familia, supleix en part Teresa pel seu esperit poc convencional i encoratja l'infant a endinsar-se en paratges prohibits. Enmig d'una clariana dins els terrenys del senyor marquès, personatge que Teresa esmentava amb una veu misteriosa, Jaume descobreix una nimfa i se n'enamora. Però l'oncle Salvador també l'abandona i Jaume se sent terriblement incomprès pels seus pares. Poc després comença a escola, experiència absolutament negativa, que només se salva per la coneixença d'un amic, Marià. Però el canvien d'escola i perd l'amic. Amb la mort de l'àvia, el dol limita les experiències de Jaume. L'obsessió per la dona de la clariana no el deixa dormir ni menjar. La mare decideix guarir-lo contant-li històries d'herois i donzelles enamorades.

A la nova escola, Jaume aconsegueix un amic inquietant, que li proposa uns jocs eròtics que en provoquen l'expulsió. Jaume aconsegueix integrar-se a l'escola, amb l'ajuda d'un mestre afectuós, juga i parla amb els companys i fins $i$ tot té una enamorada, Elvireta, amb la qual manté un curt festeig. Però no té un vertader amic, encara que progressa intel-lectualment i va guanyant la consideració de mestres i pares.

En tornar a Vilalta, dos estius després, Jaume cerca la dona de la clariana. Mentre plora, decebut per no trobar-la, veu una nimfa d'argila ajaguda a terra, amb el mateix somriure que l'havia enamorat dos estius abans. Després d'acaronar-la i besar-la fuig corrent. Se sent las i envellit. Ha de començar el batxillerat. Tot just acaba un període de la seva vida.

\section{L'ESTIL I EL LLENGUATGE}

El fet de ser un relat en primera persona, com hem comentat, en condiciona el llenguatge. Aquest és senzill i directe, adequat a l'infant protagonista, ple de sentiments, somnis, angoixes i esperances. L'estil directe i l'indirecte s'aco- 
blen perfectament. Si bé J'infant és reservat i imaginatiu, sempre fa preguntes, que els adults moltes vegades no saben contestar. De les respostes ell treu, sovint, conclusions extraordinàries. Diàlegs com aquest senyoregen el relat i el fan tendre i engrescador:

- I bé, superstició vol dir coses contràries a la fe i a la raó.

(...)

-Els Reis d'Orient, són una superstició, pare?

Vaig esperar inútilment una resposta.

-Pare...

-No siguis preguntaire, vailet.

Si desitjava conèixer la veritat de les coses, quin altre camí em restava sinó el de preguntar? El pare no era gens còmode. Valia més adreçar-se a la mare.

-Mare és una superstició la vinguda dels Reis d'Orient?

La meva pregunta semblà sorprendre-la, però es reféu de pressa.

- Una superstició, no.

-Doncs, què?

-Més aviat un miracle.

-Però és veritat?

- És clar que sí.

-Són els mateixos que varen anar a adorar Jesús?

-Els mateixos.

-Són més vells que l'avi Ramon?

-Oh.si.

-L'avi Ramon era molt vell?

- Va morir a setanta-vuit anys.

-Déu n'hi do!

L'avi Ramon caminava a poquet a poquet, s'estintolava en un bastó.

-Oi que l'avi Ramon no hauria pogut venir d'Orient, muntat en un camell?

-Ell, no. Però els Reis d'Orient són éssers extraordinaris.

-Quants anys tenen?

-Prop de dos mil.

Aquesta darrera resposta em deixà pensatiu. No podia capir una vellesa de dos mil anys (pàgs. 19-20).

EL. TEMPS I L'ESPAI

Encara que el tema és atemporal $i$ hi ha poques referències contextuals, alguns detalls situen la història a principis del segle $\mathrm{XX}$ : els viatges amb tarta- 
na, la cerimònia del dol, la necessitat de rentar la roba al rec i la presència de les revistes «Blanco y negro» $\mathrm{i}$ «La ilustración». La durada és d'uns quatre anys: comença quan Jaume encara no sap llegir i quan acaba ha de començar el batxillerat, després d'haver aprovat l'examen d'ingrés. Sembla haver-hi un error de càlcul: Jaume només ha passat tres cursos a l'escola. No sabia encara llegir als set anys? A més, el Jaume que anava de la mà de Teresa sembla de més curta edat que els sis anys que resulten d'un recompte cronològic. Ens manca almenys un any perquè la cronologia resulti encertada.

Entre els dos primers estius hi ha un lapse de temps buit molt gran: tot l'hivern. A partir del segon estiu Jaume comença a l'escola, i els esdeveniments succeits a l'hivern adquireixen importància. A partir d'aquí, els fets van succeint lentament i pausada. Els periodes de temps escolar es van marcant: el 15 de setembre comença l'escola; uns dies abans de les vacances nadalenques coneix Marià; després dels Reis, la primavera, el juliol...

Quant als espais de la novel-la, aquests vénen determinats per l'època de l'any. A l'estiu, Vilalta i Blanes. A l'hivern, Girona, definida per la mort i per l'escola. Vilalta és l'espai de la fantasia, estimulada per la mainadera Teresa. A Vilalta es troba el misteri i també l'amor per una nimfa somrient amagada en el bosc. Quan manca Teresa, l'oncle Salvador és l'encarregat d'acompanyar Jaume cap al misteri, de col-laborar a mantenir la il-lusió. Blanes, al contrari, suposa el descobriment brutal del sexe, celebrat pels cosins, els quals ignoren què és enamorar-se d'una nimfa.

Girona és la ciutat grisa i avorrida, on el centre són els pares i els mestres. També, la difícil integració amb els altres nois. Per a Jaume, representa el pragmatisme:

A mig setembre fornàvem a ciutat i la meva fantasia imaginativa es clogué com un llibre a mig llegir. Les selvàtiques arbredes emmurallades i els suposats misteris que s'hi produien es fongueren tor d" una (pàg. 41).

En morir l'avi les vacances s'acaben a la correguda i tots els actes familiars són presidits pel dol, fins que, per sort, Jaume emmalalteix i la seva mare decideix que és més important la salut del seu fill que els costums socials, i sap guarir-lo tot portant-lo al parc i contant-li històries.

La primera escola és un lloc humit, poc airejat, amb un mestre antipàtic i una llista interminable de sil.labes i nombres. Es la solitud fins que coneix Marià, l'amic coral, el qual perd quan el canvien d'escola. L'altra escola és diferent, més alegre. No hi té amics, però el mestre mostra una rialla d'orella a orella i l'ajuda a integrar-se en el grup. La ciutat, per a Jaume, representa el temor a topar Elvireta, Hilari, els companys d'estudi que se'n riuen, els cosinets i els exàmens. 


\section{ELS PERSONATGES}

Jaume és el protagonista de la història, contada a les envistes de la vellesa per ell mateix. Teresa, la seva mainadera, té una gran influència sobre el seu caràcter, imaginatiu i somniador. Quan ella desapareix de la seva vida se sent buit i desolat, en un món fred i silenciós. És sincer, com tots els infants, capaç de negar a la mare que ella l'estimi més que Teresa, amb gran obstinació.

Sovint se sent desorientat per l'actitud dels adults. La mare, per exemple, li deia que havia de ser respectuós amb els animalons del camp i, en canvi, era implacable amb les formigues, els escarabats i les mosques, i també amb qualque ratolí que es ficàs al pis. També. els grans volien que adquirís cuitura, però mai no responien a les seves preguntes.

Quan comença a escola Jaume, per primer pic, pren consciència social:

Em sorprengué de comprendre que no era jo sol a sentir aprensió $i$ recança. La major part dels nous collegials es trobaven en el mateix cas; també venien per primera vegada, es sentien separats dels pares $i$ desemparats (pàg. 42).

Jaume és amant dels llibres. Admira les persones que han sabut fer aquelles imatges que exalten la seva imaginació, però també és sensible a la natura:

El primer que va cridar-me l'atenció fou la qualitat de lombra. tan atapeida i alhora tan lluminosa. Després, la fragància del pi calent $i$ de farigola $i$, tot seguit. la xerradissa de l"ocellar. Oïa un xiulet clar $i$ agut al qual responia un xiulet idèntic. Entretant, algun ocell, també invisible, es lliurava per les branques a refilets ben musicals, enmig de la remor de la voleiadissa (pàg. 74).

Amb les insinuacions d'Hilari i les burles dels companys descobreix uns jocs que ell no s'havia plantejat i que, evidentment, tenien unes connotacions negatives des del punt de vista de la moral establerta. L'estiu següent, a Blanes, Jaume s'adona que l'amor físic l'enutja:

No desitjava veure més parelles. Temia que em fessin avorrir l'amor per sempre més. I tanmateix l'amor, com jo l'entenia, em semblava la cosa més meravellosa del món. Però després del que havia vist a la platja, sols m'abellia la solitud (pàg. 135).

El xoc és brutal, perquè Jaume entenia l'amor com un ideal, dipositat en una dona nua somrient i degotadissa enmig d'una clariana d'un bosc. Per aixd, dos anys després, en descobrir que el seu ideal no és real, sinó d'argila, i que, ajaguda a terra, encara continua amb el mateix somriure, no pot fer sinó acaronar-la i plorar sobre ella, fins que fuig corrents mentre el somni s'apaga: 
Anava corriolet enllà, cami avall. Cada pas que feia eren infinitats de distància, eternitats de temps que em separaven de la més bella illusió de la meva vida, una il.lusió que ja no podria sentir mai més.

En arribar a l'avinguda de les acàcies, em vaig sentir las i envellit (pàg. 155).

Conclou un període de la vida de Jaume i en comença un altre: ha traspassat la infancia. A partir d'aquí, l'inici del batxillerat, el camí tot dret cap a la vida adulta.

Jaume gran, el qual ens conta la seva infància des de la reflexió de la madurcsa, considera que els trets més accentuats del seu caràcter, ja definits a partir de l'estiu a Blanes, sơn: sentimentalisme, indecisio, mediocritas i, sobretot, hadoqueria (pàg. 139).

Jaume és ben petit quan divideix els personatges que l'envolten en dos grans grups: Ells eren el pare i la mare, l'àvia Laieta, els oncles i la tiela Clàudia, els cosins i tots els amics de la família. Teresa i jo formàvem un món a part $i$ els nostres secrets ningú no els havia de conèixer (pàg. 13).

Teresa era una noia simple i esquerpa, vinguda d'un poblet de muntanya, que tenia, segons sembla, dots especials per comprendre missatges de les forces ocultes de la natura, $i$ també d'interpretar els signes misteriosos de les petites coses, en aparença insignificants. Per a la mare era obstinada, rampelluda i supersticiosa. Per a Jaume, en canvi, era un ésser extraordinari, que aguditzava els sentits i deixava anar frases esgarrifoses que tot sovint endevinaven els fets succeïts més escabrosos. Li deia: Allà d'enllà hi ha un gorg on viuen nans entremaliats $i$ dones d'aigua (pàg. 14). $O$ s'aturava un momentet, esguardant amb gravetat cap a la portalada i deia i deia amb veu solemne: La propietat del senyor marquès (pàg. 9). I també: Aquí va ser on la va assassinar (pàg. 12). Heus ací un diàleg ben il-lustrador de la seva idiosincràsia:

-No t'hi has d'aturar mai, al cementiri, estaquirot!

-Per què?

Estrafeia la meva veu:

-Perquè, per què... perquè hi ha morts.

-Qué són morts, teta?

-Morts, morrs . . quina pregunta més poca solta!

-Digues-m'ho!

- Els morts són... una cosa esgarrifosa.

-Què és una cosa esgarrifosa?

-Pregunta-ho al nunci (pàg. 15).

Els pares acomiaden Teresa. Jaume l'enyora molt i emmalalteix, però es va recuperant, la vida es tot un aprenentatge $i$ una superació de pèrdues. Tanmateix, just a l'entrada de la vellesa encara es conserva el record intens de la teta que va ser fonamental per a la seva infància: 
Han passat molts d'anys. Escric aquestes notes a les envistes de la vellesa, peró si avui tornés encara a comprar sifons (suposant que en venguessin de vidres blaus $i$ verds) no en triaria mai cap d'un altre color perquè em semblaria que traeixo la memòria de Teresa (pàg. 28).

L'oncle Salvador és un eficient substitut de Teresa l'estiu segient de perdrela. És jove i optimista, bon amic de Jaume. Passegen costat per costat, sense donar-se la mà, cosa que Jaume sent com un estímul per investigar pel seu compte. L'infant sempre havia suposat que l'oncle Salvador era una mena de lladre o estafador, ja que era artista, mot que el seu pare pronunciava sempre amb un to desdenyós. Aleshores Jaume va comprendre que ser artista no era cap fet delictiu i que, a més, l'oncle compartia amb ell l'amor per la natura i els racons pintorescos, que gaudia de pintar. Per altra part, l'oncle Salvador també creia en nimfes:

-Tu les has vistes?

-Jo sí-féu tot xiroi l'oncle Salvador.

-Les pot veure tothom?

-No pas la gent prosaica.

-Què vol dir "prosaica"?

- Que només viu per a la taula i el llit. La gent prosaica no les veu mai, les Nimfes, encara que se li posin davant el nas (pàg. 32).

Els pares de Jaume, Emili i Carme, són tradicionals i amb una certa cultura, per la qual cosa defugen les supersticions. L'infant sabia bé que el seu pare era el savi de la família $\mathrm{i}$, encara que no comprengués les seves explicacions, mai no li demanava aclariments. El pare també era valent i decidit, malgrat tenir la mania de caçar conills. Resta clar el seu pragmatisme quan no vol que el seu fill continuii tocant el piano, després de la seva descoberta un estiu a Blanes, tot exclamant-se: Només ens faltaria això, un altre artista a la família! (pàg. 138). Per altra part, el pare subvalorava els contes, que només eren «mentides boniques", expressió que va provocar en Jaume un xic de repugnància seguit d'un sentiment de vergonya i culpabilitat. La mare, en canvi, sabia que, quan Jaume emmalaltia d'enyorança, calia guarir-lo amb contes i imatges meravelloses, que el fill apreciava en gran manera, donat el seu caràcter fantasiós.

Per a Jaume, la mare semblava una formigueta empeltada de cadernera, puix que li agradava molt cantar mentre feinejava (pags. 25-26). Era bona, dolça i comprensiva, i Jaume va comprendre aviat que era la millor dona del món, encara que tenia un punt negre: havia foragitat Teresa. El primer dia d'escola la recança i el sentiment d'abandó són mutus:

Quan ella fou fora del meu esguard, jo seguia veient-la amb la imaginació. Baixava l'escala ben a poc a poc, is'eixugava els ulls amb un mocadoret de batista, guarnit de randes, tot perfumat. Aquesta imatge femenina tan encisera i entendridora féu sobreeixir les meves llàgrimes (pàg. 42). 
Jaume tê dificultats de relació amb els altres nois. Marià, Hilari, Elvíreta i els cosins són els infants que un moment o altre comparteixen el protagonisme amb ell, encara que Marià és l'únic amic sincer que fa de manera espontània, malauradament per poc temps. Elvireta, una nina capritxosa i exigent, és la seva promesa per poc temps. Amb aquesta relació efímera Jaume, sempre indecís i amb manca de caràcter, aprèn a fer valer la seva voluntat i guanya prestigi entre els seus companys de l'escola, que abans gastaven un aire de superioritat davant ell i se'n burlaven quan Jaume, innocentment, gairebé es deixa embolicar per les proposicions obscenes d'Hilari, el qual ja havia estat expulsat d'una altra escola per protagonitzar $\mathrm{i}$ promoure jocs eròtics. Els cosinets Carles i Albert són just el contrari de Jaume, per això no $s$ 'hi entén gens i els defuig tot l'estiu a Blanes, refugiant-se en el piano. Per a les mares són element de comparació. Carme diu a la seva germana: $F a$ goig veure els teus dos bordegassos. Clàudia; el meu cada dia és més nyicris (pàg. 136).

Els mestres, tant per a Jaume com per a qualsevol infant, són personatges de gran importància. En aquesta novel-la en trobam dos models. El primer contacte de Jaume amb l'escola el va enfrontar amb un mestre que expressava el mateix fàstic que els seus alumnes. Badallava i mirava contínuament el rellotge i tenia el rostre cansat $i$ envellit. Cap mostra d'afecte l'acostava als seus alumnes. Si Jaume esperava alguna carícia o paraula de consol només trobà, igual que els seus condeixebles, la primera mostra d'indiferència de la seva vida; gairebé d'hostilitat. A l'altra escola, el curs següent, Jaume va perdre un amic, però trobà un mestre afable, que se li acostava amb un ample somriure i encenia en ell les ganes d'estudiar i de superar aquell etern esllanguiment per coses inassolibles. L'ajudà a integrar-se en el grup, en el qual no tenia amics, però sí bons companys $i$, amb l'ajuda d'aquest mestre, Jaume guanyà l'acceptació, també, dels pares i altres mestres pel seu esforç intel.lectual.

Si bé no és un ésser viu, tal vegada podríem considerar la nimfa com un personatge de la novel·la. De fet, en constitueix el títol i entorn d'aquesta obsessió gira la vida de Jaume durant tot el relat. A més, ell la veu com un ésser viu:

... el cos perfecte, nu i regalimant, l'abundosa cabellera mullada esparsa pel rostre i l'espatlla, el mirar benvolent i picardiós, la boca humida $i$ somrient (pàg. 154).

La nimfa de la clariana del bosc és, en realitat, una entelèquia que mena la infância de Jaume, l'amor sensual i pur que és l'altra cara del sexe que descobreix a la platja de Blanes i que ell percep com a groller. Quan la troba caiguda a terra també cau la seva il-lusió, el seu ideal. És el procés imprescindible per poder madurar, per anar fent camí cap a la vida adulta. 


\section{VISIÓ DE CONJUNT}

El mèrit de La nimfa d'argila és una recreació sensible del món dels infants. Ens torna a mostrar, com a Camins de somni, la preferència per infants tímids i somniadors, altament imaginatius, amb dificultats per relacionar-se socialment. És de destacar la gràcia dels diàlegs i també la recreació d'ambients i personatges: el misteri entorn de Teresa, la despreocupació i l'esperit antiburgès de l'oncle Salvador, la preocupació amatent de la mare. El pare, altres parents i els companys d'escola resten bastant desdibuixats, però sí compleixen la funció d'ambientar l'entorn imprescindible per a la història. Pensem que tots els esdeveniments són passats pel sedàs del punt de vista del protagonista mateix, el qual també ens els conta mitjançant el procés de manipulació inevitable del record.

\section{EL PARADIS PERDUT}

Si bé cada pèrdua, per a Jaume, suposa un acostament a la maduresa, hi ha un discurs amagat que només se'ns explica obertament a la darrera pàgina del llibre. Hí ha un cert pessimisme en la conclusió, que ens porta a un futur sense il-lusió. Una vegada aprovat l'examen d'ingrés per al batxillerat, Jaume veu clar el seu futur: trobar una o altra Elvireta, formar una família, acostar-se al model del pare, honrat funcionari, i no a l'oncle Salvador, fantasiós artista. La conclusió és: I el món seguiria giravoltant sobre el seu propi eix a través de la immensitat, desproveit de nimfes $i$ de poesia (pàg. 156). Així, doncs, la infância és el paradís perdut.

\section{L'ART I LA LITERATURA}

Hi ha un discurs ideològic entorn de l'art i la cultura. L'oncle Salvador, per dedicar-se a la pintura, és menyspreat per la família. És el seu exemple que fa que Emili no vulgui que el seu fill estudii piano. "Artista" resulta ser un mot menyspreatiu, com «lladre» o «farsant», encara que és cert que el fet de ser artista suposa no tenir ni un cèntim $i$, per tant, una certa cara dura per afrontar-ho.

Per altra part, Jaume, d'infant, valorava la lectura, perquè era una font d'afers i llocs meravellosos. Bastava mirar els gravats per endevinar-ho. Però pocs éssers eren capaços d'admirar els llibres i, per tant, els escriptors: 
Això passava cinquanta anys enrera. Llavors els toreros. les cupletistes, els clowns, els furbolistes, i encara menys les senyores de la bona societat, més o menys desvagades, no escrivien llibres. Aquesta activitat no s'havia posat de moda. La conreaven els escriptors $i$, dels escriptors, la gent en deia "ganduls". No es parlava mai de "guanyar diners» amb un llibre. Per això la gent de lletres era tan poc considerada en general, encara que, en particular, es trobés alguna que altra persona, com la mare, capaş d'admirar l'autor d'un conte o una novel.la (pàg. 39).

La conclusió sembla ser que l'activitat literària s'ha posat de moda, i la cultiven aquests grups esmentats: toreros, futbolistes, senyores de la bona societat, etc., en el moment en què Jaume ens conta la seva biografia infantil, més o menys contemporani al moment en què l'autora la va escriure. Tarımateix no resta clara la valoració d'aquest fet, malgrat el punt irònic evident, ni si els escriptors continuen considerant-se uns ganduls, igual que els pintors. Només són unes breus pinzellades, però tanmateix resta clara la contraposició: an i literatura per una banda; vida assenyada, honesta i pragmàtica per l'altra.

\section{CONCLUSIONS GENERALS}

Enllaçant amb el primer apartat d'aquest treball, el que més destaca d'aquestes dues novel-les, que és la gran sensibilitat per acostar-se al món infantil, representa una idealització de la pròpia infância de l'autora: la vida a la Rodona, la passió per la geografia, l'amor cap a la natura amb la consegüent incomprensió cap al pare caçador, la mainadera rondallaire, l'amor per un ideal i el xoc brutal a la platja de Blanes. Tot de detalls autobiogràfics que podem llegir a les Memories són compartits i reelaborats en aquestes dues novel-les. El pare de Miquel sembla ben bé Prudenci Bertrana. La mare d'Aurora, en canvi, sembla encarriada en la mare de Jaume, comprensiva i amant de la lectura. Resta clar que Aurora Bertrana és una escriptora poc imaginativa i que va bastir tota la seva obra a partir de la pròpia experiència. És altament autobiogràfica. Però ambdós protagonistes, tímids i somniadors, semblen contrastar amb el caràcter de l'autora, poc convencional i plena d'iniciatives encoratjadores i aventureres des que era un infant. Això ens fa pensar que, potser, al marge dels fets objectius i comprovables, l'autoconstrucció del personatge que Aurora Bertrana fa des dels records i la interpretació de la vellesa és més manipulada del que en algun moment havíem pogut pensar. Per altra part, hi ha una gran diferència en el desenvolupament de les dues novel-les, tal com s'ha comentat adesiara: Miquel no s'escapa del somni en què viu; Jaume, en canvi, supera les proves de maduresa que li presenta la vida. Adquireix la maduresa per sobreviure en el món real. La resposta, cal trobar-la, probablement, en el pas del temps. Encara 
que només hi ha quatre anys entre la publicació d'una i altra novel-les, Camins de somni va ser escrita molt abans, entre el 1946 i el 1947. Quan va escriure $L a$ nimfa d' argila, després de tornar de l'exili, Aurora Bertrana vivia una època de mancances morals i materials, calia adquirir el seny que l'autora sempre presumia de no haver tingut mai, i un desenllaç que encamina el protagonista cap a la vida real, malgrat el desencant evident que s'expressa al final de la novel.la, és del tot raonable.

\section{BIBLIOGRAFIA}

Bertrana, Aurora. Vértigo de horizontes. Barcelona: Torrell de Reus, 1952.

Bertrana, Aurora. Camins de somni. Barcelona: Albertí, 1955.

Bertrana, Aurora. La nimfa d'argila. Barcelona, Albertí. 1959.

Bertrana, Aurora. Matinales. Trad. D'Antoinette de Montmollin. Saint-Aubin (Suisse): À la Baconnière, 1964.

Bertrana, Aurora. Memòries fins al 1935. Barcelona: Pòrtic, 1973.

BerTrana, Aurora. Memòries del 1935 fins al retorn a Catalunya. Barcelona: Pòrtic, 1975.

- Cap d"Any. Raixa, 1960. «Notícies de fora de les terres catalanes». 